\title{
Radiological Incident Preparedness: Planning at the Local Level
}

\author{
Clive M. Tan, MBBS, MPH; Daniel J. Barnett, MD, MPH; Adam J. Stolz;
}

Jonathan M. Links, PhD

\section{ABSTRACT}

Radiological terrorism has been recognized as a probable scenario with high impact. Radiological preparedness planning at the federal and state levels has been encouraging, but translating complex doctrines into operational readiness at the local level has proved challenging. Based on the authors' experience with radiological response planning for the City of Baltimore, this article describes an integrated approach to municipal-level radiological emergency preparedness planning, provides information on resources that are useful for radiological preparedness planning, and recommends a step-by-step process toward developing the plan with relevant examples from the experience in Baltimore. Local governmental agencies constitute the first line of response and are critical to the success of the operation. This article is intended as a starting framework for local governmental efforts toward developing a response plan for radiological incidents in their communities.

(Disaster Med Public Health Preparedness. 2011;5:S151-S158)

Key Words: radiological, preparedness, terrorism, emergency, planning

$\mathrm{G}$ overnment infrastructure is at the heart of a multifaceted public health emergency preparedness system as characterized by the Institute of Medicine. ${ }^{1}$ Consistent with the principle that all disasters begin locally, ${ }^{2}$ local governmental agencies necessarily constitute the front line of response within this system. Although the all-hazards model provides a vital standardized approach for emergency operations planning and execution, there are also hazardspecific components to any preparedness plan that necessarily move beyond what the all-hazards model alone can accommodate. Local government agencies must therefore concurrently develop hazard vulnerability assessments and scenario-based plans to inform tailored jurisdictional response efforts to be implemented in concert with and supported by state and federal jurisdictions.

Within the all-hazards spectrum, radiological incidents present a uniquely challenging array of scenarios for local government emergency planning and response. These challenges derive not only from radiation's physical effects but also (in many instances, primarily) from psychosocial effects apart from the actual physical hazard. ${ }^{3,4}$ From a physical standpoint, potential health effects from radiation exposure can include both acute, deterministic effects (eg, development of acute radiation syndrome, in which severity is a function of dose) and longer-term, stochastic effects (eg, radiogenic cancers, in which risk is a function of dose). ${ }^{4}$ From a risk-perception perspective, radiological incidents have the capacity to trigger great anxiety and fear because exposure is involuntary; has short- and long- term health consequences; is potentially fatal; and is physically imperceptible, requiring sophisticated equipment for detection. ${ }^{4}$ Furthermore, a general lack of awareness about radiation health issues, coupled with a perceived inability to respond to the threat, can yield a sense of fatalism among the public and first responders alike. ${ }^{3}$

Compounding these challenges are the anticipated likelihood of radiological threats and the ubiquity of sources for such threats. Radiological terrorism has been recognized as a probable scenario with high impact, and has been listed as scenario \#11 on the federal government's list of 15 National Planning Scenarios, ${ }^{5}$ a set of high-probability threat scenarios developed by the Department of Homeland Security for use in national preparedness activities. Accordingly, radiological emergency response planning has been the focus of highvisibility, federally coordinated exercises such as TOPOFF (Top Officials) 2, conducted in 2003, and the more recent TOPOFF 4, which concluded in 2007. 6,7 Radiation sources are widely used in many industries and services, requiring not only tight security against imported sources of radiation but also vigilant monitoring of existing radiation sources. ${ }^{8}$

\section{RADIOLOGICAL EMERGENCY PREPAREDNESS PLANNING FOR BALTIMORE: A LOCAL PERSPECTIVE Purpose and Scope}

In the context of the multidimensional challenges of local emergency readiness for radiological threats, this article describes an integrated approach to municipallevel radiological emergency preparedness planning, 
as developed for use in Baltimore, Maryland (hereafter referred to as Baltimore City, to distinguish it from the adjoining but separate Baltimore County). The described approach highlights challenges and innovative opportunities that local response agencies in other jurisdictions can apply or adapt to develop their incident preparedness and response plan for radiological emergencies. This article provides information on resources that are useful for radiological preparedness planning, recommends a step-by-step process toward developing the plan, and provides relevant examples from the experience in Baltimore City.

Emergency preparedness planning for radiological incidents requires knowledge in several key areas, including strategiclevel guidance on preparedness and response to radiological incidents, ${ }^{5,9,10}$ operational-level planning and response guidance, ${ }^{11,12}$ technical response requirements for various response modules and key agencies, ${ }^{10,13,14}$ information about the health hazards of radiation and its medical management, ${ }^{4,13}$ and appropriate command and control framework and arrangements for incident management. ${ }^{11,15}$

\section{Plan Development}

The Mayor's Office of Emergency Management (MOEM) oversees disaster preparedness for Baltimore City. Many elements of a radiological incident plan have evolved in the city since the 1950s. The city's civil defense program provided a legacy of planning for nuclear attack and included numerous drills throughout the course of the Cold War. Since 2001, Baltimore City has undertaken numerous steps to improve preparedness for radiological incidents, primarily in the context of radiological terrorism. The city updated agency-level procedures for radiological incident response, purchased advanced equipment for detecting and identifying sources of radiation, trained responders, and held 5 major interagency exercises involving radiological scenarios. As of 2008, however, these new procedures and systems had not been integrated into an overarching operational document. Consolidation of these elements into a hazard-specific annex of the city's Emergency Operations Plan was initiated in 2008 as a tripartite project by MOEM, the Baltimore City Fire Department, and the Johns Hopkins Bloomberg School of Public Health.

This article details the stepwise processes this multiinstitutional team took to enhance and integrate Baltimore City's radiological preparedness planning, using evidence-informed strategies and the most current radiological planning guidance. The description of each step starts by laying out the general guidance and principles and then specifically characterizes the respective planning components that took place in Baltimore City.
Perform Background Research and Review Existing Literature

A comprehensive literature search on PubMed, governmental Web sites, professional organizations, and routine Internet search engines was conducted. The existing literature emphasizes the following areas: technical information on radiological hazards, extensive information on individual agencies and organizations responding to these incidents and their response mechanisms, training materials for responders, exercise reports and recommendations, tactical manuals for response agencies, local-level basic disaster response plans, and federal-level response plans for radiological incidents.

These materials were not directed particularly at guiding local emergency management officials to develop a radiological incident response and preparedness plan. Indeed, recent research has highlighted unique training, communication, and risk perception-related response challenges for local first receivers (hospital workers ${ }^{16,17}$ ) and first responders (emergency medical services providers ${ }^{18}$ ). These observations point to the need for additional research attention on models for enhancing local jurisdictional planning for radiological emergencies.

A few case reports were identified ${ }^{19-21}$ that retrospectively outlined the stages of planning and tasks completed for their respective radiological emergency preparedness projects. Each of these case studies offers useful information, and the style of chronological reporting provides an overarching picture of how the events unfolded. The specific case studies do not necessarily allow ready adaptation of findings for contextualized incorporation into local jurisdiction radiological planning efforts, however. For enhanced utility, this article has adopted a similar reporting style but has contextualized the scenarios and planning and illustrated the process of radiological emergency preparedness planning into discrete, achievable steps for easy execution and progress monitoring. The Examples of Table of Contents for a City Plan for Emergency Response listed in Appendix $G$ of the National Council on Radiation Protection and Measurements report No. 138 is highly useful (Figure 1) and has been extracted for reference.

\section{Determine a Project Group and a Project Manager}

Although numerous stakeholders must be consulted in the plan's development and review stages, the core project group ideally should not consist of more than 3 or 4 individuals. ${ }^{22}$ For logistic purposes and convenience of meeting, the Baltimore City project team was kept small and consisted of 3 members and 2 technical advisors. The project manager (C.M.T.) was a student at the Johns Hopkins Bloomberg School of Public Health and worked closely under the guidance of the technical advisors (J.M.L. and D.J.B.); the 2 team members were the deputy director for MOEM (A.J.S.), and the chief of hazmat operations, Baltimore City Fire Department. The Maryland Department of the Environment, the lead agency on the state's radiation control plan, was consulted on several occasions. The project team members were suitably placed in the lead and core re- 
Examples of table of contents for a city plan for emergency response. Used with permission of National Council on Radiation Protection and Measurements.

Example 1 -Emergency Response Plan for Terrorist Incidents

Table of Contents

1. Forward

2. Acknowledgements

3. Concept of Operations

4. Incident Command (direction and control)

5. Hazard Analysis (potential scenarios and effects)

6. Incident Recognition

7. Radiological Terrorism Plan Overview

8. Emergency Management
a. Mitigation
b. Preparedness
c. Response
d. Recovery

9. Agency-Specific Responsibilities

a. Mayor's Office of Emergency Management

b. City Fire Department

c. City Police Department

d. Department of Health

e. Department of Corrections

f. Hospital/Medical Facilities

g. Department of Sanitation

h. Public Department of Transportation

i. American Red Cross

j. Federal Agencies.

i. Federal Bureau of Investigation

ii. Federal Emergency Management Agency

iii. U.S. Department of Defense

iv. U.S. Department of Health and Human Services

v. U.S. Department of Transportation

vi. Public Utilities

10. Appendices
a. Notification Procedures
b. Important Notification Telephone Numbers
c. Federal Assistance
d. National Associations for Emergency Hazardous Materials Assistance
e. Medical Protoco

Example 2 -Sample Emergency Response Operations Plan

Table of Contents

Definitions

Base Plan

1. Introduction

a. Purpose

b. Scope

c. Organization

2. Policies

a. Authorities

b. Assignment of Responsibilities

c. Resource Coordination

d. Recovery Operations

e. Operations Facilities

f. Public Information

3. Situation - Disaster Condition

4. Mission

5. Concept of Operations

a. General

b. Organization

i. Management Team

ii. Emergency Support Team

iii. Field Response Team

c. Response Action

d. Responsibilities

6. Functional Annexes

a. Management and Coordination - City Incident Command System

i. Introduction

ii. Situations and Assumptions

iii. Mission

iv. Execution

v. Concept of Operations

vi. Mobilization

vii. Individual Duties and Responsibilities

viii. Communications

ix. Training

b. Law Enforcement-Sheriff Department

i. Introduction

ii. Situations and Assumptions

iii. Mission

iv. Execution

v. Concept of Operations

vi. Administration

vii. Fire Fighting/Search and Rescue

7. Hazardous Materials Response Annex

8. Health and Medical Anne

a. Patient Tracking

b. Medical Decontamination Resources

9. Communications

10. Public Works and Engineering

11. Information and Planning

12. Warning

13. Resources

14. Recovery

15. Transportation

16. Support Annexes:
a. Damage/Damage Declaration
b. Public Information/JIC
c. Evacuation and Mass Care
d. Financial Management
e. Transportation 
sponse agencies and had the authority and knowledge to make certain executive and technical decisions. The project manager was designated early on in the project for purposes of accountability and authority and was able to accommodate the project as a high-priority item. The project team met in person monthly, an important process in reinforcing commitment to the project and maintaining momentum.

\section{Understand an Ideal Response Capability}

An ideal response requires the performance of several basic functions: emergency command and control, notification and communication systems for responders and the public, emergency assessment, mitigation of hazardous conditions, and protective actions for the emergency responder and the public. At an operational level, the radiological emergency plan should clarify authority, command, and control; define organizational responsibilities; develop procedures that integrate efforts of all of the response agencies; identify logistic support, supplies, and equipment; and assess incident conditions and consequences. ${ }^{23}$

The project team discussed each of the required functions, ascertained the ideal response capability, determined the stakeholders involved, and moved on to seek the advice and buy-in of the rel- evant stakeholders. The team took time to analyze the guidelines and manuals pertaining to each functional area, met, and based on the existing capabilities and what was realistically achievable, discussed a common vision of the ideal response capability and checked back with the technical advisors from the Bloomberg School of Public Health to verify the research and analysis. The team members agreed on a plan and established this ideal response capability. Figure 2 shows a simplified version of the envisioned command structure and how the various elements for the response plan interact with one another for Baltimore City; however, the framework is generic enough to be adapted for use by other cities.

At this juncture, a project team should confer with the various stakeholders for their opinions on the realism and limitations of the proposed ideal response capability through meetings or, alternatively, through e-mail and other correspondence. Due to time limitations in Baltimore City, the project team did not directly engage all of the supporting agencies in the initial draft phase, and the decision was made to meet with them after the response plan was drafted to obtain their input on both documents, the ideal response capability and the response plan, at the same time.

\section{FIGURE 2}

Baltimore City incident response framework for radiological incidents. Adapted from International Atomic Energy Agency.

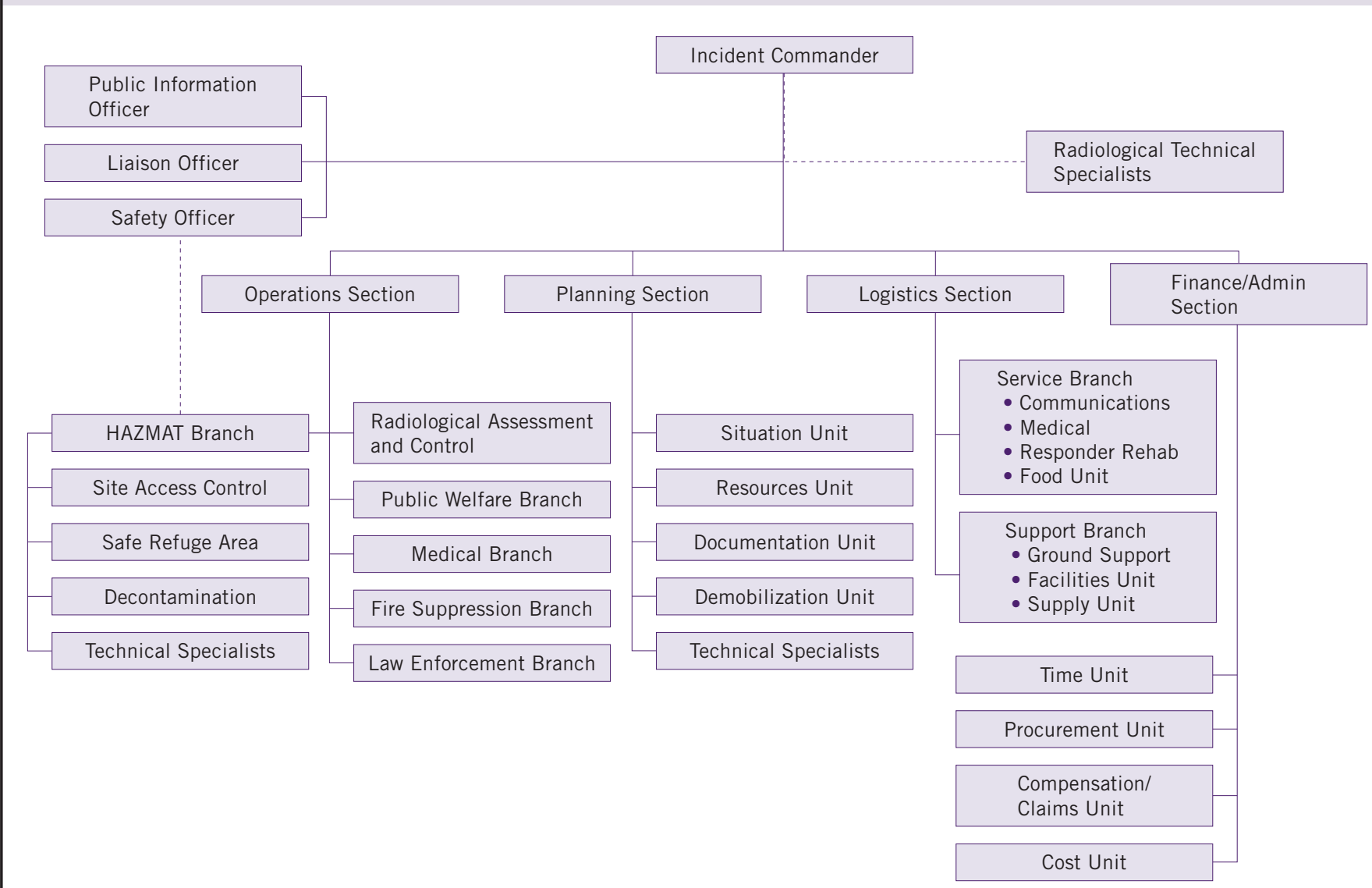




\section{Identify the Current Response Capability and Quantify and Qualify the Capability Gap}

After determining the ideal response capability, the next step is to identify the capability level of the local response and ascertain the capability gap. This can be done through focus group discussions with various stakeholders. Certain stakeholder groups may have an overly optimistic view of their capabilities, and the project team needs to be discerning and decide whether objective assessments may be required of individual agencies. Conversely, some agencies may underestimate their potential and may hold a pessimistic view of their ability to respond; they may need to be encouraged and empowered.

In Baltimore City, this project was initiated after Operation Purple Haze, a radiological dispersal device detonation simu- lation exercise conducted at M \& T Bank Stadium in Baltimore City in August 2008. Several local and regional response agencies were involved and their strengths and shortcomings were noted during the exercise and documented in the after-action report. Although not in line with the usual sequence of plan-train-exercise-evaluate, the exercise saved the project team precious time and effort trying to determine the levels of capabilities of the agencies individually. Another benefit that the project team experienced from this sequence was that the momentum generated from the exercise allowed them to obtain buy-in from the various stakeholders easily and helped keep the project on schedule. A limitation of this approach is that if the exercise outcome is poor, it could discourage the stakeholders from investing

\section{EIGURE 3}

\section{Risk Profile for Baltimore}

Risk $=\frac{[\text { Probability }] \times[\text { Human Impact }] \times[\text { Property Impact }] \times[\text { Operational Impact }] \times 100 \%}{\text { Total Possible Score of } 625}$

\begin{tabular}{|c|c|c|c|c|c|c|}
\hline & \multicolumn{4}{|c|}{ SEVERITY $=($ MAGNITUDE - MITIGATION) } & \multirow{3}{*}{ RISK } & \multirow{3}{*}{ RANK } \\
\hline & \multicolumn{4}{|c|}{ SEVERITY CLASSIFICATION - LOW, MODERATE, HIGH } & & \\
\hline & PROBABILITY & HUMAN IMPACT & $\begin{array}{c}\text { PROPERTY \& } \\
\text { ENVIRONMENTAL } \\
\text { IMPACT }\end{array}$ & $\begin{array}{l}\text { OPERATIONAL } \\
\text { IMPACT }\end{array}$ & & \\
\hline & $\begin{array}{l}\text { Relative likelihood } \\
\text { this will occur } \\
\text { within } 10 \text { years }\end{array}$ & $\begin{array}{l}\text { Possibility of } \\
\text { death or injury }\end{array}$ & $\begin{array}{l}\text { Physical losses } \\
\text { and damages }\end{array}$ & $\begin{array}{l}\text { Interruption of } \\
\text { services }\end{array}$ & $\begin{array}{c}\text { Relative } \\
\text { threat }\end{array}$ & \\
\hline SCORE & $\begin{array}{l}0=\text { N/A } \\
1=\text { Very Low } \\
2=\text { Low } \\
3=\text { Moderate } \\
4=\text { High } \\
5=\text { Very High }\end{array}$ & $\begin{array}{l}0=\mathrm{N} / \mathrm{A} \\
1=\text { Very Low } \\
2=\text { Low } \\
3=\text { Moderate } \\
4=\text { High } \\
5=\text { Very High }\end{array}$ & $\begin{array}{l}0=\text { N } / A \\
1=\text { Very Low } \\
2=\text { Low } \\
3=\text { Moderate } \\
4=\text { High } \\
5=\text { Very High }\end{array}$ & $\begin{array}{l}0=\mathrm{N} / \mathrm{A} \\
1=\text { Very Low } \\
2=\text { Low } \\
3=\text { Moderate } \\
4=\text { High } \\
5=\text { Very High }\end{array}$ & $0-100 \%$ & \\
\hline $\begin{array}{l}\text { "Dirty Bomb" } \\
\text { (RDD) detonation }\end{array}$ & 5 & 4 & 4 & 4 & $51 \%$ & 1 \\
\hline $\begin{array}{l}\text { Sealed source } \\
\text { dispersal }\end{array}$ & 4 & 2 & 1 & 1 & $1 \%$ & 7 \\
\hline $\begin{array}{c}\text { Lost or stolen } \\
\text { radioactive materials }\end{array}$ & 5 & 1 & 1 & 1 & $1 \%$ & 7 \\
\hline $\begin{array}{c}\text { Emergencies from } \\
\text { use or misuse of } \\
\text { radioactive materials }\end{array}$ & 5 & 3 & 3 & 3 & $22 \%$ & 4 \\
\hline $\begin{array}{l}\text { Transport } \\
\text { emergencies }\end{array}$ & 5 & 3 & 4 & 3 & $29 \%$ & 3 \\
\hline $\begin{array}{l}\text { Nuclear reactor } \\
\text { emergencies }\end{array}$ & 1 & 4 & 4 & 4 & $10 \%$ & 6 \\
\hline $\begin{array}{c}\text { Improvised } \\
\text { nuclear device }\end{array}$ & 2 & 5 & 5 & 5 & $40 \%$ & 2 \\
\hline Nuclear weapon & 1 & 5 & 5 & 5 & $20 \%$ & 5 \\
\hline
\end{tabular}

The original formula includes a vulnerability analysis; however, as vulnerability is not constant, but always changing as the level of preparedness changes, it will not be included in the analysis for this Figure. The total possible score of 625 is the product of $5 \times 5 \times 5 \times 5\left(-5^{4}\right)$, with 5 being the maximum score in each category. 
resources and effort in a goal that they believe may not be achievable.

\section{Perform a Risk-Vulnerability Assessment for the Local Jurisdiction}

Understanding the risk profile, vulnerabilities, and level of current preparedness will help administrators and planners understand the urgency of the project, place the project at the correct priority level, and allocate the appropriate resources to the project. If the current level of preparedness is not commensurate with the risk and vulnerability profile, then this can influence an administration to increase the priority of the project and the resources allocated to it.

An example of the risk-assessment method ${ }^{24}$ for Baltimore City is listed in Figure 3, in which the likelihood of certain events occurring has been ranked. This methodology promotes understanding of the city's level of preparedness for the events that are more likely to happen, and it guides sequentially prioritized planning for the more probable events first. In the case of a radiological response plan, this assessment helps planners focus on the types of radiological events of greatest concern. For example, a small city in close proximity to a nuclear reactor may plan more for industrial accidents, whereas a large urban jurisdiction without such proximity may focus more on terrorismrelated radiological events.

\section{Determine the Scope and Limits of Local Response}

The local response to radiological incidents is inherently resource limited. It is therefore essential to identify the available support at the state and federal levels and factor in their involvement in determining the level of the local response. Due to the limited resources at the local level, practical and selective resource allocation may prove more effective than spreading the resources diffusely. For example, when an area is contaminated with radiological fallout, the local response team will provide personnel decontamination at a suitably sited "cold zone," an area of less contamination with radiation levels that have been deemed safe. If a large area is affected, then it may be more effective for the local response team to be concentrated in a single fallout area of high radiation concentration, rather than being diffusely scattered over several locations and thus providing inadequate decontamination at any given area. External resources for reinforcing the local response can be subsequently directed to the affected areas in order of decreasing priority.

For Baltimore City, the level of support available from the surrounding counties was analyzed and the plan expanded upon existing systems to incorporate some of these regional assets into the city's response. For example, hazmat-trained personnel from neighboring county fire departments can arrive with their decontamination vehicles to assist with decontamination in the event of a large-scale, multisite incident. Decontamination vehicles and personnel will be channeled to the incident site if reinforcements are needed; otherwise, they will be directed to off-site locations such as hospitals, where the affected victims are expected to migrate. For incidents that may overwhelm even these enhanced local response capabilities, the plan factored in available state and federal assets and listed their capabilities, areas of expertise, and approximate response times.

\section{Determine What Support Is Needed From State and Federal Agencies and the Accompanying Thresholds for Action}

Identification of key resources at the state and federal levels will allow for better prioritization of local resources. At the state level, a good starting point is the Department of Energy or the Department of the Environment. At the federal level, the Federal Emergency Management Agency has outlined the roles and responsibilities of the federal agencies and maintains regional offices to assist with local planning for radiological and nuclear incidents. ${ }^{15}$ It is useful for local jurisdictions to initiate early contact with state and federal agencies to establish a working relationship and discuss what assistance they can provide the local response agencies based on the type and scale of various incidents.

For Baltimore City, the team was unable to fully engage the numerous federal agencies present in the region, despite the city's proximity to the National Capital Region. Practical considerations limited the preparedness planning and exercise planning to several stakeholders. Baltimore City worked around this limitation through engagement of key agencies that were suitably connected to other resources in their network. At the state level, the city engaged the Maryland Department of the Environment, which is located in Baltimore City, has inherent radiological incident response assets and expertise, and is well connected to other state preparedness agencies. For the Department of Defense, the city engaged the 32nd Civil Support Team (CST) of the National Guard, which is based in Maryland. The CST is familiar with and available to work with the civilian sector more readily, has extensive knowledge of the military available for large-scale radiological incident response, and can be called upon if the need arises. The military system can be complex and difficult to navigate for someone unfamiliar with the system and the CST becomes a key connector for quick access to the extensive resources and expertise of the Department of Defense.

\section{Determine a Timeline and Key Milestones}

The team should discuss and set realistic goals and deadlines for the project. Key milestones may include arranging individual meetings with various stakeholders and obtaining key information from them, holding a large meeting with stakeholders and reviewing the draft response plan, publishing and distributing the official emergency preparedness and response plan, and planning and running a preparedness exercise to evaluate the plan and the agencies' level of preparedness. The use of project management tools such as Gantt charts ${ }^{25}$ may be useful for tracking the progress of this complex, multiagency project. A simplified version of what was used for Baltimore City is provided in Figure 4. 
The project team was given 4 months to draft the plan. The unique considerations of formulating a plan at the local level required the team to share and ensure their familiarity with one another's area of specialization and assimilate theory and knowledge to develop an integrated plan while taking into consideration the practical limitations. The above-mentioned milestones will be carried out within the next 1 to 2 years to maintain the momentum of this development.

\section{Determine the Direction of Strategic Guidance, Align the Operational Plan Accordingly, and Allow This to Guide the Technical Response}

Two other important sets of documents are necessary when attempting to craft the operational preparedness plan for radiological emergencies: the basic all-hazards preparedness plan and the manuals for the standard operating procedures (SOPs) at the individual agencies (at the very least, for the lead and core agencies). The basic plan is an overarching document that contains many generic emergency response components that are essential for hazard-specific incident planning. It provides the policy and doctrinal guidance for plan development and lists the resources and procedures already present so that the hazardspecific plan can build on the existing infrastructure for en- hanced efficiency. The individual agencies' SOPs can provide useful content on the existing response capabilities and procedures, and, if appropriate, the operational response plan can incorporate them and maintain the status quo. If the SOPs are found to be inappropriate, changing the SOPs based on the new operational plan may be recommended. For Baltimore City, both documents were present and informed much of the project's content.

\section{CONCLUSIONS}

Planning for radiological incidents is complex and presents unique challenges, including management of radiation's physical and psychosocial effects. Radiological events have the capacity to trigger great anxiety and fear because radiation is physically imperceptible. This is compounded by a general lack of awareness of radiation's health effects and the perceived inability to respond to the threat. Local government agencies constitute the first line of response and are critical to the success of the operation. However, because resources at the local level are limited and variable across jurisdictions, local government agencies must assess the hazards and vulnerabilities of their jurisdictions and develop realistic scenario-based plans to inform and guide their response efforts. Having a local incident

\section{FIGURE 4}

\section{Sample Gantt Chart}

Baltimore City Radiological Response Plan

Mayor's Office of Emergency Management

\begin{tabular}{|c|c|}
\hline Project Lead: Mr Brown & \\
\hline Today's Date: 6/14/2009 & (vertical red line) \\
\hline Start Date: $1 / 12 / 2008$ & (Mon) \\
\hline
\end{tabular}

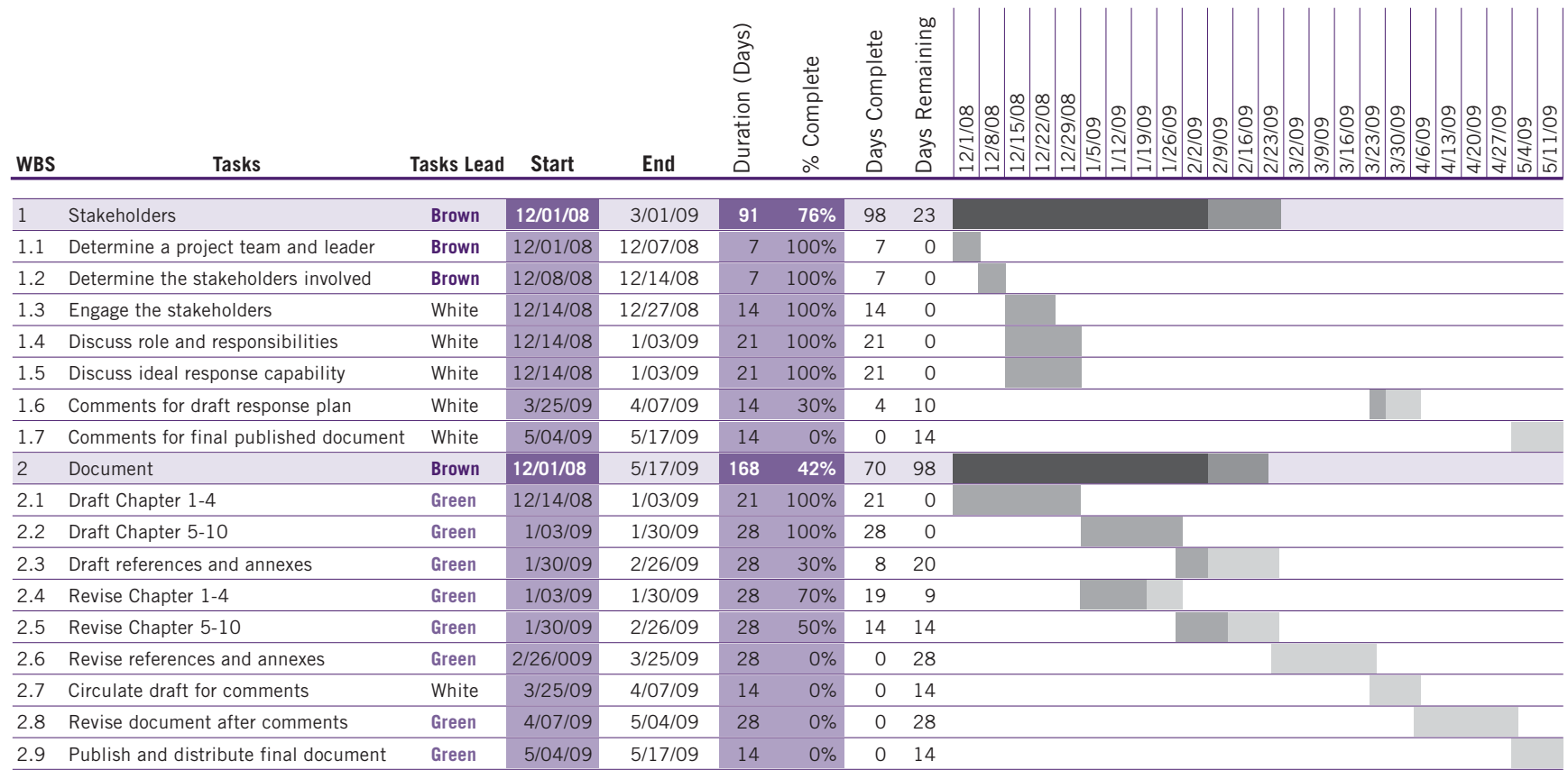


response plan is an important step in raising preparedness levels. Steps such as interagency meetings and table-top exercises can help jurisdictional stakeholders remain familiar in theory and practice with the response plan. Furthermore, such ongoing collaborative activities can and should be used to identify local readiness gaps, thus ensuring that the response plan remains a living document in the face of evolving radiological threats. Information sharing between local government agencies of different cities and their participation in state- or federallevel exercises also serve as a opportunity for benchmarking. This article's content is thus intended as a starting framework for local governmental efforts toward developing a response plan for radiological incidents in their communities.

Author Affiliations: Mr Stolz is with the City of Baltimore, Mayor's Office of Emergency Management. Drs Tan, Barnett, and Links are with Bloomberg School of Public Health, Johns Hopkins University.

Correspondence: Address correspondence and reprint requests to C. M. Tan, Army Medical Services, Singapore Armed Forces, 701 Transit Rd, \#04-01, Singapore 778910 (e-mail: cmtan@jhsph.edu).

Received for publication March 26, 2010; accepted July 2, 2010. This article was corrected on March 25, 2011.

Author Disclosures: The authors report no conflicts of interest.

\section{REFERENCES}

1. Institute of Medicine. Research Priorities in Emergency Preparedness and Response for Public Health Systems: A Letter Report. Washington, DC: The National Academies Press; 2008.

2. Taylor HA, Chaffee MW. The Navy Medicine Office of Homeland Security-A powerful organizational response to the terrorist attacks on the United States. In: Veenema TG, ed. Disaster Nursing and Emergency Preparedness for Chemical, Biological, and Radiological Terrorism and Other Hazards. New York: Springer; 2003:58.

3. Becker SM. Emergency communication and information issues in terrorist events involving radioactive materials. Biosecur Bioterror. 2004;2(3): 195-207.

4. Barnett DJ, Parker CL, Blodgett DW, Wierzba RK, Links JM. Understanding radiologic and nuclear terrorism as public health threats: preparedness and response perspectives. J Nucl Med. 2006;47(10):1653-1661.

5. Homeland Security Council. National Planning Scenarios. Scenario 11: Radiological Attack - Radiological Dispersal Devices. http://media .washingtonpost.com/wp-srv/nation/nationalsecurity/earlywarning NationalPlanningScenariosApril2005.pdf. Published April 2005. Accessed February 23, 2009.

6. Department of Homeland Security. Top Officials (TOPOFF) Exercise Series: TOPOFF 2. After Action Summary Report. http://www.dhs.gov /xlibrary/assets/T2_Report_Final_Public.doc. Published December 19, 2003.Accessed June 1, 2008.

7. Department of Homeland Security. TOPOFF 3: Exercising National Preparedness. http://www.dhs.gov/files/training/gc_1179350946764 .shtm. Published October 6, 2008. Accessed April 15, 2009.

8. Gonzalez AJ. Security of radioactive sources: the evolving new international dimensions. http://www.iaea.org/Publications/Magazines/Bulletin /Bull434/article8.pdf. Accessed June 1, 2009.
9. Federal Emergency Management Agency. Guide for All-Hazard Emergency Operations Planning, State and Local Guide (101). Chapter 6, Attachment G - Terrorism. http://www.survivalring.org/SLG-101-Annex -G-Terrorism.pdf. Published April 2001. Accessed February 23, 2009.

10. Department of Homeland Security. Target Capabilities List: A Companion to the National Preparedness Guidelines. http://www.fema.gov/pdf /government/training/tcl.pdf. Accessed February 23, 2009.

11. International Atomic Energy Agency. Emergency Preparedness and Response. Method for Developing Arrangements for Response to a Nuclear or Radiological Emergency. http://www-pub.iaea.org/mtcd/publications /pdf/method2003_web.pdf. Published October 2003. Accessed February 23, 2009.

12. International Atomic Energy Agency. Emergency Preparedness and Response. Manual for First Responders to a Radiological Emergency. http: //www-pub.iaea.org/MTCD/publications/PDF/epr_Firstresponder_web .pdf. Published October 2006. Accessed February 23, 2009.

13. American College of Radiology Disaster Planning Task Force. Disaster Preparedness for Radiology Professionals: Response to Radiological Terrorism, Government Version 3.0. www.acr.org/ . . /DisasterPreparedness /ACRsDisasterPreparednessPrimer/ACRDisasterPreparedness Primer2006Doc1.aspx. Published 2006. Accessed June 6, 2009.

14. Musolino SV, Harper FT. Emergency response guidance for the first 48 hours after the outdoor detonation of an explosive radiological dispersal device. Health Phys. 2006;90(4):377-385.

15. Federal Emergency Management Agency. Introduction to Incident Command System (ICS-100.A), Student Manual., http://www.training.fema .gov/EMIWeb/IS/is100lst.asp. Published April 2008. Accessed February 23, 2009.

16. Veenema TG, Walden B, Feinstein N, Williams JP. Factors affecting hospitalbased nurses' willingness to respond to a radiation emergency. Disaster Med Public Health Prep. 2008;2(4):224-229.

17. Becker SM, Middleton SA. Improving hospital preparedness for radiological terrorism: perspectives from emergency department physicians and nurses. Disaster Med Public Health Prep. 2008;2(3):174-184.

18. Dimaggio C, Markenson D, T Loo G, Redlener I. The willingness of U.S. Emergency Medical Technicians to respond to terrorist incidents. Biosecur Bioterror. 2005;3(4):331-337.

19. Sharp TW, Brennan RJ, Keim M, Williams RJ, Eitzen E, Lillibridge S. Medical preparedness for a terrorist incident involving chemical or biological agents during the 1996 Atlanta Olympic Games. Ann Emerg Med. 1998; 32(2):214-223.

20. Kamenopoulou V, Dimitriou P, Hourdakis CJ, et al. Nuclear security and radiological preparedness for the Olympic Games, Athens 2004: lessons learned for organizing major public events. Health Phys. 2006;91(4):318330.

21. Savkin MN, Sneve MK, Grachev MI, Frolov GP, Shinkarev SM, Jaworska A. Medical and radiological aspects of emergency preparedness and response at SevRAO facilities. J Radiol Prot. 2008;28(4):499-509.

22. Putnam D. Team size can be the key to a successful project. http://www .qsm.com/process_01.html. Published 2000. Accessed June 6, 2009.

23. Management of Terrorist Events Involving Radioactive Material. (Report No. 138) . Bethesda, MD: National Council on Radiation Protection and Measurements; 2001: 125-134.

24. Kaiser Foundation Health Plan. Medical center hazard vulnerability analysis. http://www.njha.com/ep/pdf/627200834041PM.pdf. Published 2001. Accessed February 23, 2009.

25. Wilson JM. Gantt charts: a centenary appreciation. Eur J Oper Res. 2003; 149:430-437. 